\title{
Flag leaf vein traits and their correlation with photosynthesis and grain yield in wheat genotypes of differing ploidy
}

\author{
H.M. XU' ${ }^{1}$, Y.L. CHEN ${ }^{2}$, and Y.Y. LI ${ }^{2 *}$ \\ College of Forestry, Northwest A\&F University, Yangling 712100, Shaanxi, P.R. China ${ }^{1}$ \\ State Key Laboratory of Soil Erosion and Dryland Farming on the Loess Plateau, Institute of Soil \\ and Water Conservation, Northwest A\&F University, Yangling 712100, Shaanxi, P.R. China ${ }^{2}$
}

\begin{abstract}
Leaf venation and coupled physiological function of wild plants co-evolve during the natural selection. How artificial selection affects leaf vein traits and coordinated physiological functions of main crops are largely unknown. This study examined the changes of leaf vein traits and their correlation with gas exchange of flag leaves and yield in eight wheat genotypes of differing ploidy under the same growing conditions. The results indicate that flag leaf vein density (VLA), major-vein density $\left(\mathrm{VLA}_{\text {major }}\right.$ ), and minor-vein density $\left(\mathrm{VLA}_{\text {minor }}\right)$ decreased whereas the proportion of minor-vein length and interveinal distance between small longitudinal veins (IVD) increased during the polyploidization process, and the major advance occurred from the period from diploids to tetraploids. The VLA, VLA $A_{\text {major }}$, and VLA $\mathrm{V}_{\text {minor }}$ were closely coordinated with maximum net photosynthetic rate $\left(\mathrm{P}_{\mathrm{N}}\right)$ and photosynthetic $\mathrm{N}$ use efficiency (PNUE), but not with stomatal conductance. The proportion of minor-vein length and IVD were negatively related with $\mathrm{P}_{\mathrm{N}}$ and PNUE but positively related with $\mathrm{N}$ content per area $\left(\mathrm{N}_{\text {area }}\right)$ during wheat evolution. A higher proportion of minor-vein length and IVD, and a lower $\mathrm{VLA}_{\text {major }}$ in flag leaves along with a larger $\mathrm{N}_{\text {area }}$ were largely responsible for the increased yield in modern cultivars. The decreased redundancy of leaf vein density and increased minor-vein proportion in modern cultivars can confer a yield advantage during wheat evolution.
\end{abstract}

Additional key words: evolution, gas exchange, leaf $\mathrm{N}$ content, stomatal conductance,-Triticum aestivum.

\section{Introduction}

Leaf veins are an important constituents of leaf structure. They provide mechanical support, transport nutrients and water for photosynthesis and transpiration through the xylem, and transport photosynthates and signal molecules from the mesophyll to the rest of the plant through the phloem (Niklas 1999, Roth-Nebelsick et al. 2001). Depending on climatic and environmental conditions during leaf development, leaf vein traits are highly diverse across and within species (Uhl and Mosbrugger 1999, Boyce et al. 2008, Sack et al. 2012, Sack and Scoffoni 2013). Leaf vein traits have shown repeated evolutionary trajectories across major plant groups. Throughout 380 million years of evolution, angiosperm vein densities (vein length per leaf area, VLA) have reached $8 \sim 25 \mathrm{~mm} \mathrm{~mm}^{-2}$ (about $2 \mathrm{~mm} \mathrm{~mm}^{-2}$ in non-angiosperms) with increasing number of vein orders. High value of leaf VLA enables unparalleled photosynthetic rate and transpiration rate in the angiosperms than their competitors, thus dominate in a range of habitats than other plant lineages (Boyce et al. 2009). In the evolution of $\mathrm{C}_{4}$ within eudicot genera Cleome and Flaveria, leaf VLA increased from $\mathrm{C}_{3}$ to $\mathrm{C}_{3} / \mathrm{C}_{4}$ intermediate and $\mathrm{C}_{4}$ species (Marshall et al. 2007, McKown and Dengler 2007). $\mathrm{C}_{4}$ grasses have evolved a higher VLA (2.1 times of $\mathrm{C}_{3}$ grasses), denser transverse veins and denser small longitudinal veins than the $\mathrm{C}_{3}$ grasses without significant difference in large longitudinal veins (Ueno et al. 2006). Increasing VLA may initially have little effect on the performance of an effective $\mathrm{CO}_{2}$ concentration mechanism, but may enhance the water status of $\mathrm{C}_{4}$ leaves in hot environments (Sage 2004). Compared to the natural evolution, crop evolution is mainly made by artificial selection. Wheat, as one of the oldest and most important of cereal crops worldwide, began to domesticate $\sim 10000$ years ago (Tanno and Willcox 2006). Modern cultivars of the Triticum aestivum hexaploids with large grain yield were domesticated from the more primitive diploids and

Submitted 23 April 2020, last revision 4 June 2020, accepted 9 June 2020.

Abbreviations: $\mathrm{g}_{\mathrm{s}}$ - stomatal conductance; IVD - interveinal distance between small longitudial veins; LMA - leaf mass per area; $\mathrm{N}_{\text {area }}$ $\mathrm{N}$ content per area; $\mathrm{N}_{\text {mass }}-\mathrm{N}$ content per mass; NRE - $\mathrm{N}$ remobilization efficiency; $\mathrm{P}_{\mathrm{N}}$ - net photosynthetic rate; PNUE - photosynthetic

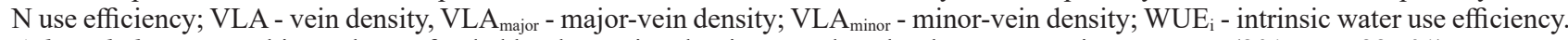
Acknowledgements: This work was funded by the National Science and Technology Supporting Program (2015BAD22B01).

*Corresponding author; e-mail: yyli@ms.iswc.ac.cn 
tetraploids, and polyploidization played an important role during the cultivation and breeding of wheat. How the leaf vein traits changed during this polyploidization process was largely not clear.

Leaf vein traits have been reported to closely associate with leaf physiological function. Generally, high VLA values are positively correlated with higher leaf hydraulic conductance, greater stomatal density and stomatal conductance, and higher rate of gas exchange per unit leaf area (Sack and Frole 2006, Brodribb et al. 2007, Brodribb and Jordan 2011, Zhang et al. 2012, Sack and Scoffoni 2013). But this is not so under all cases. Negative (Nardini and Salleo 2000, Sack and Scoffoni 2012) and no correlations (Flexas et al. 2013, Xiong et al. 2015, Gleason et al. 2016) have also been reported between leaf VLA and leaf hydraulic conductance. Leaf VLA is negatively correlated with leaf net photosynthetic rate $\left(\mathrm{P}_{\mathrm{N}}\right)$ and stomatal conductance $\left(\mathrm{g}_{\mathrm{s}}\right)$ in rice cultivars under different water status (Tabassum et al. 2016). Leaf VLA shows no apparent association with stomatal conductance and maximal net $\mathrm{CO}_{2}$ assimilation across a diverse group of 35 evergreen Australian angiosperms (Gleason et al. 2016). These inconsistent results indicate that the evolutionary drivers linking leaf vein traits and hydraulic efficiency or gas exchange are not fully understood. Moreover, leaf VLA was reported to be positively related with $\mathrm{N}$ and $\mathrm{P}$ resorption efficiencies across 17 dipterocarp tree species (Zhang et al. 2015). Another study found that leaf VLA is not correlated with leaf $\mathrm{N}$ content per area $\left(\mathrm{N}_{\text {area }}\right)$, but interveinal distance is positively correlated with leaf $\mathrm{N}_{\text {area }}$ among 11 rice cultivars (Xiong et al. 2015). How leaf vein traits are coordinated with these leaf physiological functions during wheat evolutionary process is yet to be known. Knowledge on such comprehensive correlations between leaf vein traits and leaf physiological traits is critical for enhancing our understanding of leaf structural attributes to crop water use and photosynthesis.

Despite the potential importance of leaf vein traits, few studies have examined associations between these traits and whole plant performance. Leaf vein traits are weakly, but significantly related to tree demographic performance (relative growth rate and mortality) along soil environments for 54 co-occurring species in a subtropical forest (Iida et al. 2016). Increasing leaf vein vensity via mutagenesis in rice results in an enhanced photosynthetic efficiency without increased transpiration (Feldman et al. 2017). Leaf VLA is positively correlated with the grain yield in 292 rice landraces (Nawarathna et al. 2017), suggesting that the higher VLA can be used in future rice breeding programs. Whether leaf vein traits in wheat have the similar associations with yield potential as in rice remains unknown. Identification of the presence of such leaf vein traits will be helpful to future wheat breeding.

Some morphological and physiological changes have been reported among wheat species differing in ploidy (Evans and Dunstone 1970, Austin et al. 1982, Zhang et al. 2002, Xiong et al. 2006, Huang et al. 2007, Li et al. 2014, Wang et al. 2017). The diploids generally have smaller leaf area, higher stomatal frequencies, and smaller mesophyll cells than the hexaploids, net photosynthetic rate is the highest in diploids, intermediate in tetraploids, and the lowest in hexaploids (Austin et al. 1982), but the hexaploids have higher root water uptake capacity, higher yield and water use efficiency, as well as higher drought resistance (longer survival duration and higher yield stability under drought) (Zhang et al. 2002, Xiong et al. 2006, Wang et al. 2017). However, little is known about variation of leaf vein traits and their potential importance in leaf physiological function and yield increment during the evolutionary process. Therefore, the aim of this study was to examine the variation of leaf vein traits, physiological function, yield, and their relationship in eight wheat species of three different ploidy. We assumed that during wheat evolution from diploids to tetraploids and to hexaploids, leaf VLA increased as that directed by natural selection, and leaf VLA is closely coordinated with gas exchange and yield.

\section{Materials and methods}

Plants and treatments: Eight species, including two diploids, two tetraploids, and four hexaploids, were used in a field experiment in Yangling, Shaanxi Province in China (Table 1 Suppl.). Soil was silty clay with $\mathrm{pH} 8.36$, bulk density $1.26 \mathrm{~g} \mathrm{~cm}^{-3}$, organic matter $13.6 \mathrm{~g} \mathrm{~kg}^{-1}$, total $\mathrm{N} 0.82 \mathrm{~g} \mathrm{~kg}^{-1}$, alkaline $\mathrm{N} 78.4 \mathrm{mg} \mathrm{kg}^{-1}$, Olsen-P $14.2 \mathrm{mg}$ $\mathrm{kg}^{-1}$, and available $\mathrm{K} 210.2 \mathrm{mg} \mathrm{kg}^{-1}$. Seeds were sown on 11 October 2018 at a spacing of $5 \times 15 \mathrm{~cm}$ in plots $2 \times 3 \mathrm{~m}^{2}$. There were three replicate plots of each species arranged in randomized blocks. Each plot received $0.0225 \mathrm{~kg}(\mathrm{~N}) \mathrm{m}^{-2}$ and $0.012 \mathrm{~kg}\left(\mathrm{P}_{2} \mathrm{O}_{5}\right) \mathrm{m}^{-2}, 70 \%$ of $\mathrm{N}$ fertilizer and all $\mathrm{P}$ fertilizer were applied before sowing, the left $30 \%$ of $\mathrm{N}$ fertilizer was applied with precipitation during the jointing stage. The precipitation during the whole growth season (11. 10. 2018 - 16.6. 2019) was $252 \mathrm{~mm}$, and $30 \mathrm{~mm}$ of irrigation was added in the winter of 2018. During the end of May 2019, the plots were sprayed with chemicals at the manufacturer's recommended rate to prevent aphid. Weeds were pulled out manually.

The flowering date of each species was labeled with tags, and 13 main stems in each plot of each species were labeled. Two tagged flag leaves were used for the measurements of leaf area and leaf vein traits on the fourth day after flowering, two tagged flag leaves were used for the measurement of gas exchange parameters and photosynthetic $\mathrm{N}$ use efficiency (PNUE) at the same period, and the left nine flag leaves was used for determination of leaf mass per area (LMA) and N remobilization efficiency.

Measurement of leaf vein traits: Two flag leaves per plot per species were scanned with a scanner at first, and the leaf images were analyzed for leaf area using imageJ software (https://imagej.en.softonic.com/), then the two leaves were used to determined leaf vein traits, totally six leaves per species. Two $0.5 \mathrm{~cm}^{2}$ pieces were quickly excised from the middle portion of each leaf, and preserved in FAA [37 \% (m/v) aqueous formaldehyde, $50 \%(\mathrm{v} / \mathrm{v})$ ethanol, and $13 \%(\mathrm{~m} / \mathrm{v})$ glacial acetic acid] until use. The fixed pieces were boiled in $70 \%$ ethanol for about 10 20 min 
and washed several times in distilled water, the leaf pieces were transferred to boiling $85 \%(\mathrm{~m} / \mathrm{v})$ lactic acid for $20 \mathrm{~min}$, and then stored in chloral hydrate-saturated ethanol before analysis (Ueno 1995). Four fields per pieces was randomly taken using a light microscope ( $C X 31$, Olympus, Tokyo, Japan) and attached digital camera system (M-shot, Sci-Tech Cor., Guangzhou, China), and above mentioned imageJ software was used to analyzed vein traits. Wheat vascular bundles can be categorized into four types: midvein (MV), large longitudinal veins (LLVs), small longitudinal veins (SLVs), and transverse veins (TVs) (Nelson and Dengler 1997). In the present study, the major-vein density $\left(\mathrm{VLA}_{\text {major }}, \mathrm{mm} \mathrm{mm}^{-2}\right.$ ) was the sum of the densities of the MV and LLVs, and the minor-vein density $\left(\mathrm{VLA}_{\text {minor, }} \mathrm{mm} \mathrm{mm}^{-2}\right.$ ) was the sum of the densities of the SLVs and TVs. Vein density and the proportion of minor-vein length [\%] were also calculated, and interveinal distance between two neighboring SLVs (IVD) were also measured.

Measurement of gas exchange, intrinsic water use efficiency $\left(W_{U} E_{i}\right)$, and photosynthetic $\mathrm{N}$ use efficiency (PNUE): Gas exchange was measured using a portable gas-exchange system (LI-6400, Li-Cor, Lincoln, NE, USA) from 9:30 to 11:30 on sunny days, and the radiation source was set to a photosynthetic photon flux density (PPFD) of $1200 \mu \mathrm{mol} \mathrm{m} \mathrm{m}^{-2} \mathrm{~s}^{-1}$. The ambient temperature, relative humidity, and $\mathrm{CO}_{2}$ concentration were 28.4 - $33.2{ }^{\circ} \mathrm{C}$, $35.5-46.8 \%$ and $400-412 \mu \mathrm{mol} \mathrm{mol}{ }^{-1}$, respectively. The leaf enclosed in the chamber of the portable gas-exchange system was marked for identifying the projected areas after each measurement. Then the leaf was cut and taken to the lab for determination of $\mathrm{N}$ content per area $\left(\mathrm{N}_{\text {area }}\right)$. Leaf $\mathrm{N}$ content was determined using an Auto-Kjeldahl method (Kjeltec system 2300 Distilling Unit, Foss, Hoganas, Sweden). The $\mathrm{WUE}_{\mathrm{i}}$ was calculated as $\mathrm{P}_{\mathrm{N}} / \mathrm{g}_{\mathrm{s}}$, and the PNUE was calculated as $\mathrm{P}_{\mathrm{N}} / \mathrm{N}_{\text {area }}$.

Measurement of $\mathrm{N}$ remobilization efficiency (NRE) and leaf mass per area (LMA) in flag leaves: The NRE was used to represent the phloem transport capacity. $\mathrm{N}$ content based on leaf area and dry mass was determined on three dates. Flag leaf $\mathrm{N}$ content reached the maximum on the date of flowering for modern wheat cultivars (Cai et al. 2008), but we are not sure if this was true in primitive wheat species. So, we sampled on the date of flowering, the fourth day after flowering, and at physiological maturity, and three flag leaves were taken away at each date per plot per species. These leaves were scanned first, then killed at $105{ }^{\circ} \mathrm{C}$ for $30 \mathrm{~min}$, later oven-dried at $80{ }^{\circ} \mathrm{C}$ to a constant mass. The scanned pictures were used for determining leaf area with imageJ software, and leaf mass per area (LMA) was calculated as leaf dry mass/leaf area. The dried leaves were grounded for determination of $\mathrm{N}$ content. $\mathrm{N}$ content on the fourth day after flower were always larger than those on the day of flowering, so we take $\mathrm{N}$ content on the fourth day as the maximum $\mathrm{N}$ content $\left(\mathrm{N}_{\max }\right)$. $\mathrm{N}$ content based on leaf area and leaf dry matter are strongly correlated $\left(R^{2}=0.87, P<0.01, n=72\right)$, so we use only $\mathrm{N}$ content per dry mass to calculate $\mathrm{N}$ remobilization efficiency
(NRE) (Zhang et al. 2014) as NRE [\%] $=\left(\mathrm{N}_{\max }-\mathrm{N}_{\text {maturity }}\right)$ $\times 100 / \mathrm{N}_{\max }$, where $\mathrm{N}_{\text {maturity }}$ is the $\mathrm{N}$ content per dry matter at maturity.

Grain yield: At physiological maturity of each species, $1 \mathrm{~m}^{2}$ of each plot was harvested to determine aboveground biomass and grain yield; biomass and grain were weighted after oven-drying at $80^{\circ} \mathrm{C}$ for $3 \mathrm{~d}$.

Statistical analyses: Two-level nested analysis of variance (ANOVA) was used to assess the significance of leaf vein and physiological parameters across different wheat ploidy. A post-hoc multiple comparison was conducted using the Tukey-Kramer method if the effect of ploidy was significant. A principal component analysis (PCA) was analyzed to examine multivariate associations of leaf traits. The allometric relationships between leaf vein traits and leaf area, LMA were modeled by power functions, and the regressions between leaf vein traits and leaf physiological parameters, biomass and yield were fitted by linear models. The nested ANOVA was conducted by a "two-level nested anova" EXCEL file provided by Dr. J.H. McDonald on the webpage (http://www.biostathandbook. com/nestedanova.html), all other statistics were conducted using SPSS Statistics 20.0 software (IBM Corporate, Armonk, USA).

\section{Results}

Both flag leaf area and LMA in diploids were significantly lower than in tetraploids and hexaploids. Flag leaf area was the lowest in diploids $\left(11.43 \mathrm{~cm}^{2}\right)$, intermediate in hexaploids $\left(26.19 \mathrm{~cm}^{2}\right)$, and the largest in tetraploids $\left(31.80 \mathrm{~cm}^{2}\right)$. The LMA increased from $40.96 \mathrm{~g} \mathrm{~m}^{-2}$ in diploids to $56.72 \mathrm{~g} \mathrm{~m}^{-2}$ in tetraploids, and $53.36 \mathrm{~g} \mathrm{~m}^{-2}$ in hexaploids. For leaf vein traits, diploids had significantly higher VLA, VLA $\mathrm{V}_{\text {major }}$, and $\mathrm{VLA}_{\text {minor }}$, and lower proportion of minor-vein length and IVD than tetraploids and hexaploids. No significant difference of the above vein traits was found between tetraploids and hexaploids except $\mathrm{VLA}_{\text {major }}$, which was $14.7 \%$ higher in tetraploids than in hexaploids (Table 1). These results suggested that the evolution of wheat leaf vein traits mainly occurred during the period from diploids to tetraploids. VLA, VLA major, and $\mathrm{VLA}_{\text {minor }}$ were significantly and positively correlated (VLA $v s$. VLA major $: R^{2}=0.87, P<0.01$; VLA $v s$. VLA minor: $_{\text {: }}$ : $R^{2}=0.96, P<0.001$; VLA major $_{v}$. $\mathrm{VLA}_{\text {minor }}: R^{2}=0.72$, $P<0.01$ ), and they were negatively correlated with IVD $\left(R^{2}=0.96, P<0.001\right.$ for VLA; $R^{2}=0.83, P<0.01$ for $\mathrm{VLA}_{\text {major }} ; R^{2}=0.94, P<0.001$ for $\mathrm{VLA}_{\text {minor }}$ ). Proportion of minor-vein length was negatively correlated with $\mathrm{VLA}_{\text {major }}$ $\left(R^{2}=0.79, P<0.01\right)$.

VLA, VLA $A_{\text {major }}$, and VLA minor $_{\text {across wheat genotypes of }}$ differing ploidy decreased with leaf area (pseudo $R^{2}=0.74$, $P<0.01$ for VLA; pseudo $R^{2}=0.66, P<0.05$ for VLA $\mathrm{VLajor}_{\text {, }}$ and pseudo $R^{2}=0.76, P<0.05$ for $\mathrm{VLA}_{\text {minor }}$ ) (Fig. $1 A$ ), while proportion of minor-vein length and IVD increased with leaf area (pseudo $R^{2}=0.46, P=0.06$ for proportion of minor-vein length; pseudo $R^{2}=0.53, P<0.05$ for the 
Table 1. Flag leaf area $\left[\mathrm{cm}^{2}\right]$, leaf mass per area (LMA) $\left[\mathrm{g} \mathrm{m}^{-2}\right]$, vein density $\left[\mathrm{mm} \mathrm{mm}^{-2}\right]$, proportion of minor-vein length (Proportion) [\%], and interveinal distance between two neighboring small longitudinal veins (IVD) [mm] in eight wheat genotypes, including two diploids (D1 and D2), two tetraploids (T1 and T2), and four hexaploids (H1-FC3, H2-ZM101, H3-CW134, and H4-XY6). Means \pm SEs, $n=6$. Different letters indicate significant differences between wheat genotypes of differing ploidy at $P<0.05$.

\begin{tabular}{llllllll}
\hline Genotype & Leaf area & LMA & $\begin{array}{l}\text { Vein density } \\
\text { major }\end{array}$ & minor & total & Proportion & IVD \\
& & & & & & \\
\hline D1 & $12.90 \pm 1.29$ & $41.93 \pm 0.83$ & 1.420 .03 & $4.21 \pm 0.05$ & $5.63 \pm 0.04$ & $74.84 \pm 0.54$ & $0.192 \pm 0.004$ \\
D2 & $9.96 \pm 1.08$ & $39.98 \pm 0.79$ & $1.32 \pm 0.05$ & $4.28 \pm 0.08$ & $5.60 \pm 0.09$ & $76.47 \pm 0.74$ & $0.205 \pm 0.002$ \\
Diploid mean & $11.43 \pm 0.92 \mathrm{c}$ & $40.96 \pm 0.62 \mathrm{~b}$ & $1.37 \pm 0.03 \mathrm{a}$ & $4.25 \pm 0.05 \mathrm{a}$ & $5.61 \pm 0.05 \mathrm{a}$ & $75.66 \pm 0.50 \mathrm{~b}$ & $0.198 \pm 0.003 \mathrm{~b}$ \\
T1 & $35.34 \pm 1.91$ & $55.72 \pm 1.13$ & $0.84 \pm 0.04$ & $3.43 \pm 0.05$ & $4.26 \pm 0.04$ & $80.33 \pm 0.87$ & $0.261 \pm 0.004$ \\
T2 & $28.26 \pm 1.39$ & $57.72 \pm 1.72$ & $0.88 \pm 0.04$ & $3.15 \pm 0.10$ & $4.03 \pm 0.11$ & $78.09 \pm 0.96$ & $0.283 \pm 0.009$ \\
Tetraploid mean & $31.80 \pm 1.55 \mathrm{a}$ & $56.72 \pm 1.05 \mathrm{a}$ & $0.86 \pm 0.03 \mathrm{~b}$ & $3.29 \pm 0.07 \mathrm{~b}$ & $4.15 \pm 0.06 \mathrm{~b}$ & $79.21 \pm 0.70 \mathrm{a}$ & $0.272 \pm 0.006 \mathrm{a}$ \\
H1-FC3 & $29.33 \pm 2.66$ & $51.07 \pm 0.62$ & $0.75 \pm 0.03$ & $3.29 \pm 0.17$ & $4.03 \pm 0.16$ & $81.63 \pm 1.13$ & $0.293 \pm 0.013$ \\
H2-ZM101 & $19.96 \pm 1.62$ & $52.01 \pm 1.19$ & $0.74 \pm 0.03$ & $3.13 \pm 0.07$ & $3.87 \pm 0.05$ & $80.89 \pm 0.87$ & $0.311 \pm 0.005$ \\
H3-CW134 & $24.33 \pm 1.85$ & $52.77 \pm 1.31$ & $0.78 \pm 0.03$ & $3.84 \pm 0.10$ & $4.62 \pm 0.09$ & $83.09 \pm 0.79$ & $0.252 \pm 0.007$ \\
H4-XY6 & $31.14 \pm 1.62$ & $57.59 \pm 1.20$ & $0.73 \pm 0.05$ & $2.91 \pm 0.10$ & $3.64 \pm 0.07$ & $79.84 \pm 1.53$ & $0.322 \pm 0.011$ \\
Hexaploid mean & $26.19 \pm 1.30 \mathrm{~b}$ & $53.36 \pm 0.74 \mathrm{a}$ & $0.75 \pm 0.02 \mathrm{c}$ & $3.29 \pm 0.09 \mathrm{~b}$ & $4.04 \pm 0.09 \mathrm{~b}$ & $81.36 \pm 0.58 \mathrm{a}$ & $0.295 \pm 0.007 \mathrm{a}$ \\
\hline
\end{tabular}

Table 2. Flag leaf net photosynthetic rate $\left(\mathrm{P}_{\mathrm{N}}\right)\left[\mu \mathrm{mol} \mathrm{m} \mathrm{m}^{-2} \mathrm{~s}^{-1}\right]$, stomatal conductance $\left(\mathrm{g}_{\mathrm{s}}\right)\left[\mathrm{mol} \mathrm{m} \mathrm{m}^{-2} \mathrm{~s}^{-1}\right], \mathrm{N}$ content per area $\left(\mathrm{N}_{\text {area }}\right)\left[\mathrm{g} \mathrm{m}^{-2}\right]$, intrinsic water use efficiency $\left(\mathrm{WUE}_{\mathrm{i}}=\mathrm{P}_{\mathrm{N}} / \mathrm{g}_{\mathrm{s}}\right.$ ) $\left[\mu \mathrm{mol} \mathrm{mmol} \mathrm{m}^{-1}\right.$, photosynthetic $\mathrm{N}$ use efficiency (PNUE $=\mathrm{P}_{\mathrm{N}} / \mathrm{N}_{\text {area }}$ ) [ $\left.\mu \mathrm{mol} \mathrm{g}^{-1} \mathrm{~s}^{-1}\right]$, and $\mathrm{N}$ remobilization efficiency (NRE) [\%] in eight wheat genotypes, including two diploids (D1 and D2), two tetraploids (T1 and T2), and four hexaploids (H1-FC3, H2-ZM101, H3-CW134, and H4-XY6). Means $\pm \mathrm{SEs}, n=6$ for $\mathrm{P}_{\mathrm{N}}, \mathrm{g}_{\mathrm{s}}, \mathrm{N}_{\mathrm{area}}$, WUE $\mathrm{W}_{\mathrm{i}}$, and PNUE, and $n=3$ for NRE. Different letters indicate significant differences between wheat genotypes of differing ploidy at $P<0.05$.

\begin{tabular}{|c|c|c|c|c|c|c|}
\hline Genotype & $P_{N}$ & $\mathrm{~g}_{\mathrm{s}}$ & $\mathrm{N}_{\text {area }}$ & $\mathrm{WUE}_{\mathrm{i}}$ & PNUE & NRE \\
\hline D1 & $25.30 \pm 0.90$ & $0.38 \pm 0.03$ & $1.35 \pm 0.10$ & $69.01 \pm 6.95$ & $19.28 \pm 1.40$ & $80.78 \pm 2.36$ \\
\hline D2 & $23.97 \pm 0.81$ & $0.44 \pm 0.02$ & $1.45 \pm 0.05$ & $54.45 \pm 3.53$ & $16.65 \pm 0.72$ & $86.02 \pm 0.66$ \\
\hline Diploid mean & $24.63 \pm 0.61 \mathrm{a}$ & $0.41 \pm 0.02$ & $1.40 \pm 0.06 \mathrm{a}$ & $61.73 \pm 4.32$ & $17.96 \pm 0.85 \mathrm{a}$ & $83.40 \pm 1.61$ \\
\hline $\mathrm{T} 1$ & $19.88 \pm 0.31$ & $0.38 \pm 0.03$ & $2.20 \pm 0.09$ & $54.03 \pm 4.30$ & $9.12 \pm 0.38$ & $86.16 \pm 0.26$ \\
\hline $\mathrm{T} 2$ & $21.12 \pm 0.28$ & $0.47 \pm 0.05$ & $2.17 \pm 0.07$ & $48.01 \pm 5.69$ & $9.76 \pm 0.28$ & $80.08 \pm 3.43$ \\
\hline Tetraploid mean & $20.50 \pm 0.27 b$ & $0.42 \pm 0.03$ & $2.18 \pm 0.06 b$ & $51.02 \pm 3.52$ & $9.44 \pm 0.25 b$ & $83.12 \pm 2.05$ \\
\hline H1-FC3 & $21.12 \pm 0.70$ & $0.53 \pm 0.05$ & $2.15 \pm 0.08$ & $41.75 \pm 4.53$ & $9.95 \pm 0.67$ & $83.57 \pm 1.66$ \\
\hline H2-ZM101 & $19.25 \pm 0.69$ & $0.26 \pm 0.02$ & $1.92 \pm 0.11$ & $76.02 \pm 6.45$ & $10.10 \pm 0.35$ & $84.45 \pm 2.12$ \\
\hline H3-CW134 & $19.74 \pm 1.12$ & $0.28 \pm 0.03$ & $2.09 \pm 0.10$ & $72.29 \pm 5.35$ & $9.55 \pm 0.60$ & $70.51 \pm 2.75$ \\
\hline H4-XY6 & $18.53 \pm 0.74$ & $0.32 \pm 0.04$ & $2.15 \pm 0.03$ & $62.97 \pm 7.16$ & $8.61 \pm 0.31$ & $85.05 \pm 0.52$ \\
\hline Hexaploid mean & $19.66 \pm 0.43 b$ & $0.35 \pm 0.03$ & $2.08 \pm 0.04 b$ & $63.26 \pm 3.92$ & $9.55 \pm 0.27 b$ & $80.90 \pm 2.00$ \\
\hline
\end{tabular}

IVD) (Fig. $1 B, C$ ). Due to the strong correlation between flag leaf area and $\operatorname{LMA}\left(R^{2}=0.81, P<0.01\right)$, the variation of leaf vein traits with LMA followed the same trend as with leaf area (Fig. 1 Suppl.). The allometric relationship may partly explain the trend of leaf vein traits during the wheat polyploidization.

The diploids had 20.1 and $25.3 \%$ higher in $\mathrm{P}_{\mathrm{N}}, 90.2$ and $88.1 \%$ higher PNUE, 35.8 and $32.3 \%$ lower in $\mathrm{N}_{\text {area }}$ than tetraploids and hexaploids, respectively. No difference of these parameters was observed between tetraploids and hexaploids. There was no difference in $\mathrm{g}_{\mathrm{s}}, \mathrm{WUE}_{\mathrm{i}}$, and NRE among genotypes with differing ploidy (Table 2). The $\mathrm{P}_{\mathrm{N}}$ was not correlated with $\mathrm{g}_{\mathrm{s}}\left(\mathrm{R}^{2}=0.21, \mathrm{P}>0.05\right)$, PNUE was positively correlated with $\mathrm{P}_{\mathrm{N}}\left(R^{2}=0.90, P<0.001\right), \mathrm{WUE}_{\mathrm{i}}$ was negatively correlated with $\mathrm{g}_{\mathrm{s}}\left(R^{2}=0.86, P<0.01\right)$, and $\mathrm{N}_{\text {area }}$ was negatively correlated with $\mathrm{P}_{\mathrm{N}}\left(R^{2}=0.75\right.$, $P<0.01)$ and PNUE $\left(R^{2}=0.94, P<0.001\right)$ (Fig. 2 Suppl.).

The PCA was employed to evaluate how leaf vein traits and leaf physiological function were associated. The
PCA axis 1 , accounting for $64.83 \%$ of the total variation, showed strong loadings on all five leaf vein traits and some physiological parameters like $\mathrm{P}_{\mathrm{N}}$, PNUE, and $\mathrm{N}_{\text {area }}$. PCA axis 2, accounting for $20.6 \%$ of the total variation, showed strong loadings on $\mathrm{g}_{\mathrm{s}}$ and $\mathrm{WUE}_{\mathrm{i}}$ (Fig. 3 Suppl.). The VLA, VLA $A_{\text {major }}$, and $\mathrm{VLA}_{\text {minor }}$ were significantly and positively correlated with $\mathrm{P}_{\mathrm{N}}\left(R^{2}=0.81, P<0.01\right.$ for VLA; $R^{2}=0.90, P<0.001$ for $\mathrm{VLA}_{\text {major }}$, and $R^{2}=0.67, P<0.05$ for $\left.\mathrm{VLA}_{\text {minor }}\right)$ and PNUE $\left(R^{2}=0.84, P<0.01\right.$ for VLA; $R^{2}=0.95, P<0.001$ for $\mathrm{VLA}_{\text {major }}$, and $R^{2}=0.71, P<0.01$ for $\mathrm{VLA}_{\text {minor }}$ ) (Fig. 2), but proportion of minor-vein length and IVD were significantly and negatively correlated with $\mathrm{P}_{\mathrm{N}}\left(R^{2}=0.69, P<0.05\right.$ for proportion of minor-vein length and $R^{2}=0.77, P<0.01$ for IVD) (Fig. 2) and PNUE $\left(R^{2}=0.70, P 0.05\right.$ for proportion of minor-vein length and $R^{2}=0.75, P<0.01$ for IVD) (Fig. 2). The VLA, VLA $A_{\text {major }}$, and $\mathrm{VLA}_{\text {minor }}$ decreased with increased $\mathrm{N}_{\text {area }}$, but proportion of minor-vein length and IVD increased with $\mathrm{N}_{\text {area }}$ (Figs. 2 and 3). 
Biomass was positively related to leaf area $\left(R^{2}=0.63\right.$, $P<0.05)$, proportion of minor-vein length $\left(R^{2}=0.67\right.$, $P<0.05)$, and $\mathrm{N}_{\text {area }}\left(R^{2}=0.58, P<0.05\right)$, but negatively related to $\operatorname{VLA}_{\text {major }}\left(R^{2}=0.61, P<0.05\right), \mathrm{P}_{\mathrm{N}}\left(R^{2}=0.55\right.$,

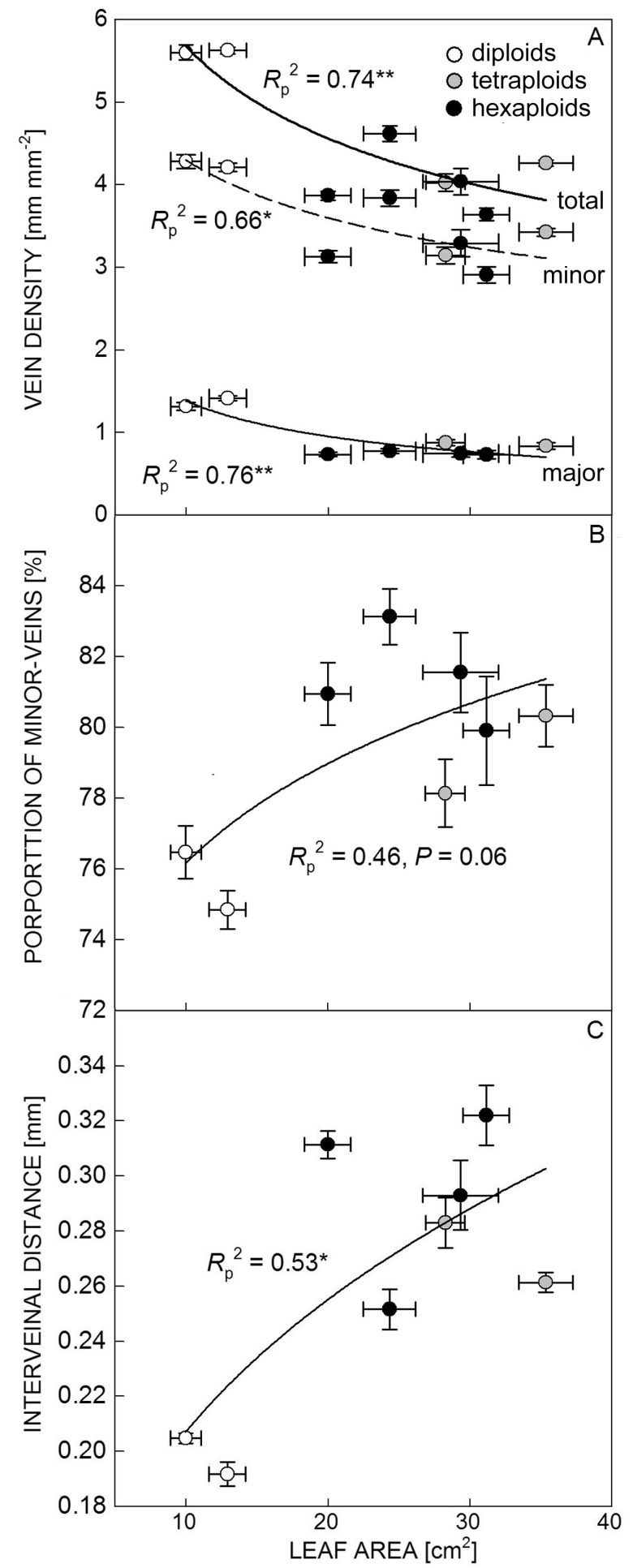

Fig. 1. Allometric relationships between flag leaf vein density $(A)$, proportion of minor-veins $(B)$ and interveinal distance $(C)$, and leaf area across eight wheat genotypes of differing ploidy. Means \pm SEs, $n=6$. The curves are fitted by a power function; $R_{\mathrm{p}}{ }^{2}$ - pseudo $R^{2}$ of modeling curves. * $-P<0.05, * *-P<0.01$.
$P<0.05)$, and PNUE $\left(R^{2}=0.58, P<0.05\right)$ (Table 2 Suppl.). Grain yield was positively related with proportion of minor-vein length $\left(R^{2}=0.88, P<0.01\right)$, IVD $\left(R^{2}=0.51, P<0.05\right)$, and $\mathrm{N}_{\text {area }}\left(R^{2}=0.49, P=0.053\right)$, but negatively related with VLA $\left(R^{2}=0.49, P=0.055\right)$, VLA $_{\text {major }}\left(R^{2}=0.75, P<0.01\right), \mathrm{P}_{\mathrm{N}}(0.62, P<0.05), \mathrm{N}_{\text {area }}$ $\left(R^{2}=0.49, P=0.053\right)$, and PNUE $\left(R^{2}=0.58, P<0.05\right)$ (Table 2 Suppl.). The above relationship suggested that higher proportion of minor-vein length, larger IVD, and increased $\mathrm{N}$ content contribute to the biomass and yield improvement during the process of wheat evolution.

\section{Discussion}

During the evolution of wheat, VLA, VLA $\mathrm{Vajor}_{\text {, and }}$ $\mathrm{VLA}_{\text {minor }}$ all show the trend to decrease, while proportion of minor-vein length and IVD increased (Table 1). This trend differs from that exhibited in angiosperm and $\mathrm{C}_{4}$ grasses evolution (Boyce et al. 2009, Ueno et al. 2006). The variation of wheat leaf vein traits across differing ploidy can be partly explained by the developmental algorithm for vein formation during leaf expansion, showing declined major-vein density with increasing leaf size, and minor-vein density independent of leaf size (Sack et al. 2012). Generally, major veins include the first three orders of veins, and vein density of these three orders declines with leaf area (Sack et al. 2012). The first two orders of veins (midrib and large longitudinal veins) of wheat leaves are directly connected with leaf sheath, and participate in water transport to leaves, photosynthate export, etc. (Altus

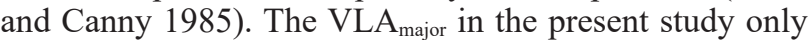
covered the first two orders of veins and it decreased due to the increased flag leaf area during wheat evolution process. Vein density of the third order of veins (small longitudinal veins) also decreased with increased leaf area and it contributed more than $60 \%$ to VLA and $75 \%$ to VLA $_{\text {minor }}$ (data not shown), resulting in decreased VLA and $\mathrm{VLA}_{\text {minor }}$ during wheat evolutionary process. Meanwhile, we found that proportion of minor-vein length and IVD increased with the increase in leaf area (Fig. 1). Although there is no mechanic association between LMA and vein traits (Sack et al. 2013), the changes of vein traits with LMA also showed the same trend as those with flag leaf area during the study since LMA and leaf area are closely related.

Higher VLA in diploid than in tetraploid and hexaploid species may favour their photosynthesis. The earlier studies (Evans and Dunstone 1970, Austin et al. 1982) and present study all supported that the more primitive diploids have higher net photosynthetic rate than modern hexaploid cultivars. Except the role of mechanical support, majorvein density has been found to play a role in determining the water transport capacity, in damage tolerance of the vein system, and in leaf drought tolerance (Sack et al. 2008, Scoffoni et al. 2011). Thus larger major-vein density in diploids provide better water transport and so enable their better survival in harsh environments than tetraploids and hexaploids although some research do not support this (Xiong et al. 2006, Wang et al. 2017). The minor veins 
(transverse veins and small longitudinal veins) of wheat leaves play a vital role in lateral transport of photosynthates from the small to the large longitudinal veins (Altus and Canny 1982) because they have large surface area for uploading photosynthates from the surrounding mesophyll. Thus, diploids have acquired a better photosynthate translocation system than the tetraploids and hexaploids to match with their higher photosynthetic capacity. The decreased $\mathrm{VLA}_{\text {major }}$ in tetraploid and hexaploid species may reduce the carbon cost for construction, and lower vein projected area might potentially enhance mesophyll radiation capture (Sack and Scoffoni 2013), and larger IVD may allow more mesophyll cells occupy (Austin et al. 1982).

Past studies showed VLA (especially VLA $_{\text {minor }}$ ) is closely correlated with $\mathrm{g}_{\mathrm{s}}$, and $\mathrm{P}_{\mathrm{N}}$ at intraspecific and interspecific levels (Sack and Frole 2006, Brodribb et al. 2007, Brodribb and Jordan 2011, Zhang et al. 2012, Sack and Scoffoni 2013). This study also supported the strong positive association between VLA and $\mathrm{P}_{\mathrm{N}}$ (Fig. 2), but leaf vein density and $g_{s}$ was decoupled (Fig. 3 Suppl.). The $\mathrm{P}_{\mathrm{N}}$ and $\mathrm{g}_{\mathrm{s}}$ also decoupled across wheat genotypes of differing ploidy (Fig. 3 Suppl.). In an early study by Austin et al. (1982), the mean $g_{s}$ of the diploids was only $5 \%$ greater than that of genotypes in this study; $\mathrm{g}_{\mathrm{s}}$ in diploids was $17.1 \%$ higher than that of hexaploid cultivars with no statistic difference, indicating leaf internal anatomical features rather than the difference of $g_{s}$ mainly drive the variation in photosynthetic rate. Anatomically, small leaf size, small mesophyll cell size, and close spacing of veins are correlated with high photosynthetic rate in primitive genotypes (Dunstone and Evans 1974). Water supply capacity of leaves did not constrain water loss and $\mathrm{CO}_{2}$ diffusion under present ample soil water condition. Although there are reports of increased water and nutrient use efficiency during the wheat evolution process (Zhang et al. 2002, Xiong et al. 2006, Huang et al. 2007), we did not find this at leaf level. Leaf $\mathrm{WUE}_{\mathrm{i}}$ did not change and PNUE decreased (Table 2), which were possibly related with the selected genotypes and different expressions in water and nutrient use efficiency at different organ levels. Leaf veins traits were closely associated with PNUE but not related with $\mathrm{WUE}_{\mathrm{i}}$ since $\mathrm{WUE}_{\mathrm{i}}$ was mainly determined by $g_{s}$, and PNUE was mainly determined by $P_{N}$ (Fig. 3 Suppl.).

Theoretically, leaves acclimated to higher nutrient supplies would have vein traits associated with higher leaf hydraulic conductance and gas exchange rate (Sack and Scoffoni 2013). VLA across rice cultivars was independent of $\mathrm{N}_{\text {area, }}$ but IVD was positively correlated with $\mathrm{N}_{\text {area }}$ (Xiong et al. 2015). In this study, we found $\mathrm{N}_{\text {area }}$ was negatively correlated with VLA, VLA major, and VLA minor,

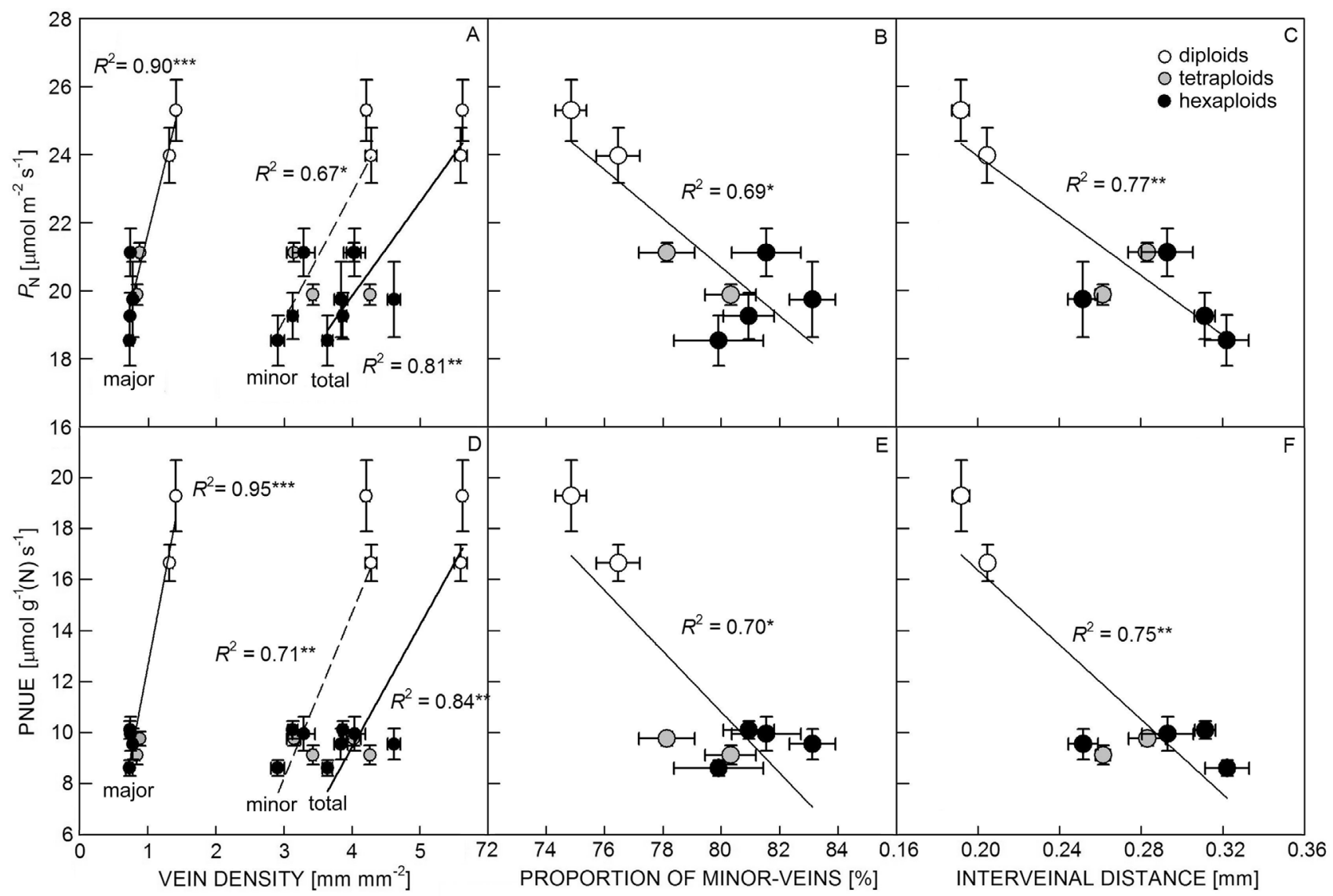

Fig. 2. Relationships between net photosynthetic rate $\left(\mathrm{P}_{\mathrm{N}}\right)$ or photosynthetic $\mathrm{N}$ use efficiency (PNUE), and leaf vein density $\left(A, D\right.$, respectively), proportion of minor-veins $\left(B, E\right.$, respectively) and interveinal distance $\left(C, F\right.$, respectively) ${ }_{\mathrm{n}}$ in wheat genotypes with differing ploidy. Means \pm SEs, $n=6{ }^{*}{ }^{*} P<0.05, * *-P<0.01, * * *-P<0.001$. 
and positively correlated with proportion of minor-vein length as well as IVD (Fig. 3). This can be explained by the developmental algorithm for vein formation (Sack et al. 2012) because leaf higher $\mathrm{N}$ content is accompanied with larger leaf area $\left(R^{2}=0.88, P<0.01\right)$. Although higher $\mathrm{N}$ content stimulated proportion of minor-vein length, $\mathrm{N}$ remobilization efficiency did not change during wheat

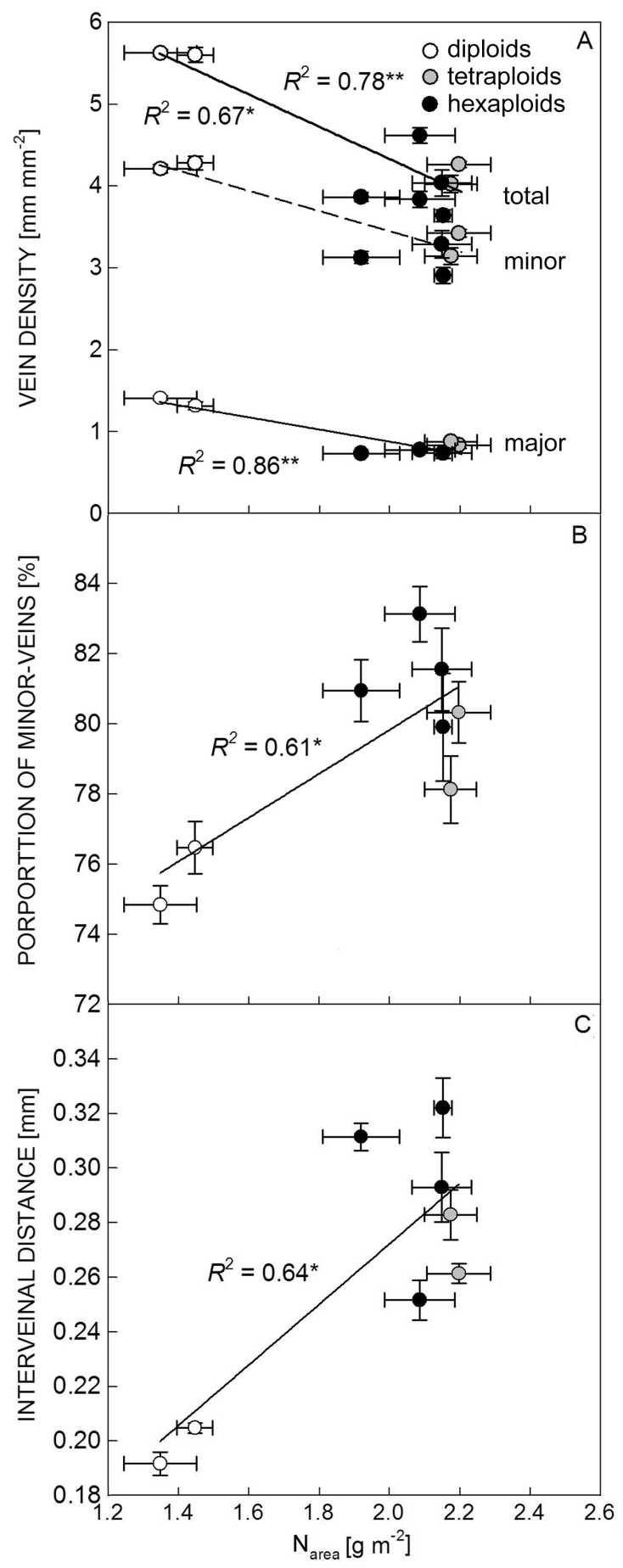

Fig. 3. Relationships between leaf vein density $(A)$, proportion of minor-veins $(B)$ and interveinal distance $(C)$, and $\mathrm{N}$ content per area $\left(\mathrm{N}_{\text {area }}\right)$ in wheat genotypes with differing ploidy. Means \pm SEs, $n=6 . *-P<0.05, * *-P<0.01$. evolution, the reason may be related to enlarged interveinal distance at higher $\mathrm{N}$ content, which increased distance for photosynthate transport to phloem. Leaf phloem transport was a complex process, and $\mathrm{N}$ remobilization efficiency may be affected by many factors, such as the distribution of phloem in the vein network, and on species' loading strategies, post-flowering leaf duration period, grain sink size, etc. Even tetraploids and hexaploids had higher $\mathrm{N}_{\text {area }}$, their $\mathrm{P}_{\mathrm{N}}$ was lower than that of diploids, showing high $\mathrm{N}$ content in the tetraploids and hexaploids did not increase photosynthesis, contrasted with the studies claiming that leaf $\mathrm{N}$ content was closely linked to maximum assimilation across species (Field and Mooney 1986, Harrington et al. 1989, Wright et al. 2004). The reason may be related to lower $\mathrm{N}$ content allocation to the photosynthetic apparatus or high $\mathrm{N}$ demand in tetraploids and haxaploids.

The biggest evolution advance of leaf vein and physiological traits occurred during the period from diploids to tetraploids, thereafter they changed little. Tetraploid Triticum dicoccoides (AABB) hybridized with Aegilops squarrosa (DD) to give rise to the cultivated hexaploid wheats. So, the increased D genome changed the leaf vein traits and physiological function a little and did not increase the photosynthesis. Watanabe et al. (1997) found that the increased doses of the D genome reduces photosynthesis, but the depression is dependent on the source of the D genome. This study partly supports their finding. Although there were not much difference in vein traits and physiological function between tetraploids and hexaploids, hexaploids achieved a higher yield than tetraploids, the relevant mechanism needs further study.

We found at leaf level, that larger biomass mainly attributed to the increase in leaf area, proportion of minor-vein length and $\mathrm{N}_{\text {area}}$, while high yield was mainly attributed to increased proportion of minor-vein length, IVD, and $\mathrm{N}_{\text {area }}$ during the process of wheat evolution. It was not possible to determine the relative importance of each trait, but both $\mathrm{VLA}_{\text {major }}$ and proportion of minor-vein length showed closer association with yield than other leaf traits, and also linked with leaf physiological function like $\mathrm{N}_{\text {area }}, \mathrm{P}_{\mathrm{N}}$, and PNUE, so they are important leaf attributes for yield increase in modern cultivars. Modern wheat genotypes may improve the carbon allocation proportion to grain production due to artificial selection by lowering carbon construction cost in leaf main veins (decreased $\mathrm{VLA}_{\text {major }}$ ) and/or by optimizing carbon distribution pattern among different orders of leaf vein system (increased proportion of minor-vein length). In contrast to the study in rice, where VLA was positively correlated with the grain yield (Feldman et al. 2017, Nawarathna et al. 2017), the potential of vein traits in future wheat breeding needs further testing.

Modern cultivars of the hexaploid Triticum aeativum produce larger grain yield than the more primitive diploid and tetraploid species despite they have lower $\mathrm{P}_{\mathrm{N}}$ (Evans and Dunstone 1970, Austin et al. 1982). So, $\mathrm{P}_{\mathrm{N}}$ is not the reason of yield increase during wheat domestication, the increase in harvest index, grain, and leaf size, aboveground biomass, the proportion of dry mass mobilized to the grain and water and nutrient use efficiency may be the other major 
factors in the selection of wheat varieties for increasing yield (Dunstone et al. 1973, Zhang et al. 2002, Xiong et al. 2006, Huang et al. 2007, Wang et al. 2017). This study showed decreased VLA $_{\text {major }}$ and increased proportion of minor-vein length were also closely associated with the yield improvement during wheat evolution. These traits are worthy to be further assessed in future wheat breeding.

\section{Conclusions}

The VLA, VLA $A_{\text {major }}$ and VLA $_{\text {minor }}$ decreased while proportion of minor-vein length and interveinal distance increased during wheat evolution, and the major advance occurred from diploids to tetraploids. VLA, VLA major, and VLA $A_{\text {minor }}$ were closely correlated with $P_{\mathrm{N}}$ and PNUE but not with $\mathrm{g}_{\mathrm{s}}$. Proportion of minor-vein length and interveinal distance was positively related with $\mathrm{N}_{\text {area }}$ and negatively with $\mathrm{P}_{\mathrm{N}}$ and PNUE, respectively, during wheat evolution. Higher proportion of minor-vein length and interveinal distance, lower $\mathrm{VLA}_{\text {major }}$ along with increased $\mathrm{N}_{\text {area }}$ in flag leaves were largely responsible for the increased yield in modern cultivars. This study demonstrates that evolution of leaf vein density in wheat is different from those in wild plants, but a high coordination still exists between leaf vein density and $\mathrm{P}_{\mathrm{N}}$. The study highlights the proportion of minor-vein length, IVD, and $\mathrm{VLA}_{\text {major }}$ as the potential indexes for future wheat high yield breeding.

\section{References}

Altus, D.P., Canny, M.J.: Water pathways in wheat leaves I. The division of fluxes between different vein types. - Aust. J. Plant Physiol. 12: 173-181, 1985.

Austin, R.B., Morgan, C.L., Ford, M.A., Bhagwat, S.G.: Flag leaf photosynthesis of Triticum aestivum and related diploid and tetraploid species. - Ann. Bot. 49: 177-189, 1982.

Boyce, C.K., Brodribb, T.J., Field, T.S., Zwieniecki, M.A.: Angiosperm leaf vein evolution was physiologically and environmentally transformative. - Proc. roy. Soc. B 276: 1771-1776, 2008.

Brodribb, T.J., Field, T.S., Jordan, G.J.: Leaf maximum photosynthetic rate and venation are linked by hydraulics. Plant Physiol. 144: 1890-1898, 2007.

Brodribb, T.J., Jordan, G.J.: Water supply and demand remain balanced during leaf acclimation of Nothofagus cunninghamii trees. - New Phytol. 192: 437-448, 2011.

Cai, R.G., Zhang, M., Yin, Y.P., Wang, P., Zhang, T.B., Gu, F., Dai, Z.M., Liang, T.B., Wu, Y.H., Wang, Z.L.: Photosynthetic characteristics and antioxidative metabolism of flag leaves in responses to nitrogen application in wheat during grain filling. - Sci. agr. sin. 41: 53-62, 2008.

Dunstone, R.L., Evans, L.T.: Role of changes in cell size in the evolution of wheat. - Aust. J. Plant Physiol. 1: 157-165, 1974.

Dunstone, R.L., Gifford, R.M., Evans, L.T.: Photosynthetic characteristics of modern and primitive wheat species in relation to ontogeny and adaptation to light. - Aust. J. biol. Sci. 26: 295-307, 1973.

Evans, L.T., Dunstone, R.L.: Some physiological aspects of evolution in wheat. - Aust. J. biol. Sci. 23: 725-741, 1970.

Feldman, A.B., Leung, H., Baraoidan, M., Elmido-Mabilangan, A., Canicosa, I., Quick, W.P., Sheehy, J., Murchie, E.H.:
Increasing leaf vein density via mutagenesis in rice results in an enhanced rate of photosynthesis, smaller cell sizes and can reduce interveinal mesophyll cell number. - Front. Plant Sci. 8: $1883,2017$.

Field, C., Mooney, H.: The photosynthesis-nitrogen relationship in wild plants. - In: Givnish, T.J. (ed.): On the Economy of Plant Form and Function. Pp. 25-55. Cambridge Press, Cambridge 1986.

Flexas, J., Scoffoni, C., Gago, J., Sack, L.: Leaf mesophyll conductance and leaf hydraulic conductance: an introduction to their measurement and coordination. - J. exp. Bot. 64: 3965-3981, 2013.

Gleason, S.M., Blackman, C.J., Chang, Y., Cook, A.M., Laws, C.A., Westoby, M.: Weak coordination among petiole, leaf, vein, and gas-exchange traits across Australian angiosperm species and its possible implications. - Ecol. Evol. 6: 267-278, 2016.

Harrington, R.A., Brown, B.J., Reich, P.B., Fownes, J.H.: Ecophysiology of exotic and native shrubs in Southern Wisconsin. II. Annual growth and carbon gain. - Oecologia 80: 368-373, 1989.

Huang, M.L., Deng, X.P., Zhao, Y.Z., Zhou, S.L., Inanaga, S., Yamada, S., Tanaka, K.: Water and nutrient use efficiency in diploid, tetraploid and hexaploidy wheat. - J. integr. Plant Biol. 49: 706-715, 2007.

Iida, Y., Sun, I.F., Price, C.A., Chen, C.T., Chen, Z.S., Chiang, J.M., Huang, C.L., Swenson, N.G.: Linking leaf veins to growth and mortality rates: an example from a subtropical tree community. - Ecol. Evol. 6: 6085-6096, 2016.

Li, P.F., Cheng, Z.G., Ma, B.L., Palta, J.A., Kong, H.Y., Mo, F., Wang, J.Y., Zhu, Y., Lv, G.C., Batool, A., Bai, X., Li, F.M., Xiong, Y.C.: Dryland wheat domestication changed the development of aboveground architecture for a wellstructured canopy. -. PLoS ONE 9: e95825, 2014.

Marshall, D.M., Muhaidat, R., Brown, N.J., Liu, Z., Stanley, S., Griffiths, H., Sage, R.F., Hibberd, J.M.: Cleome, a genus closely related to Arabidopsis, contains species spanning a developmental progression from $\mathrm{C}_{3}$ to $\mathrm{C}_{4}$ photosynthesis. Plant J. 51: 886-896, 2007.

McKown, A.D., Dengler, N.G.: Key innovations in the evolution of Kranz anatomy and C4 vein pattern in Flaveria (Asteraceae). - Amer. J. Bot. 94: 382-399, 2007.

Nardini, A., Salleo, S.: Limitation of stomatal conductance by hydraulic traits: sensing or preventing xylem cavitation? Trees 15: 14-24, 2000.

Nawarathna, R.N., Dassanayake, K.B., Nissanka, S.P., Seneweera, S., Salisbury, P.: Is phenotypic variability in leaf vein density in rice associated with grain yield? - J. Rice Res. Develop. 1: 1-9, 2017.

Nelson, T., Dengler, N.: Leaf vascular pattern formation. - Plant Cell 9: 1121-1135, 1997.

Niklas, K.J.: A mechanical perspective on foliage leaf form and function. - New Phytol. 143: 19-31, 1999.

Ocheltree, T.W., Nippert, J.B., Kirkham, M.B., Prasad, P.V.V.: Partitioning hydraulic resistance in Sorghum bicolor leaves reveals unique correlations with stomatal conductance during drought. - Funct. Plant Biol. 41: 25-36, 2014.

Roth-Nebelsick, A., Uhl, D., Mosbrugger, V., Kerp, H.: Evolution and function of leaf venation architecture: a review. - Ann. Bot. 87: 553-566, 2001.

Sack, L., Dietrich, E.M., Streeter, C.M., Sanchez-Gomez, D., Holbrook, N.M. Leaf palmate venation and vascular redundancy confer tolerance of hydraulic disruption. - Proc. nat. Acad. Sci. USA 105: 1567-1572, 2008.

Sack, L., Frole, K.: Leaf structural diversity is related to hydraulic capacity in tropical rain forest trees. - Ecology 87: 483-491, 
2006.

Sack, L., Scoffoni, C.: Measurement of leaf hydraulic conductance and stomatal conductance and their responses to irradiance and dehydration using the evaporative flux method (EFM). - J. Visualized Exp. 70: e4179, 2012.

Sack, L., Scoffoni, C.: Leaf venation: structure, function, development, evolution, ecology and applications in the past, present and future. - New Phytol. 198: 983-1000, 2013.

Sack, L., Scoffoni, C., John, G.P., Poorter, H., Mason, C.M., Mendez-Alonzo, R., Donovan, L.A.: How do leaf veins influence the worldwide leaf economic spectrum? Review and synthesis. - J. exp. Bot. 64: 4053-4080, 2013.

Sack, L., Scoffoni, C., McKown, A.D., Frole, K., Rawls, M., Havran, J.C., Tran, H., Tran, T.: Developmentally based scaling of leaf venation architecture explains global ecological patterns. - Nat. Commun. 3: 837, 2012.

Sage, R.F.: The evolution of $\mathrm{C}_{4}$ photosynthesis. - New Phytol. 161: 341-370, 2004

Scoffoni, C., Rawls, M., McKown, A.D., Cochard, H., Sack, L.: Decline of leaf hydraulic conductance with dehydration: relationship to leaf size and venation architecture. - Plant Physiol. 156: 832-843, 2011.

Tabassum, M.A., Zhu, G.L., Hafeez, A., Wahid, M.A., Shaban, M., Li, Y.: Influence of leaf vein density and thickness on hydraulic conductance and photosynthesis in rice (Oryza sativa L.) during water stress. - Sci. Rep. 6: 36894, 2016.

Tanno, K., Willcox, G.: How fast was wild wheat domesticated? - Science 311: 1886, 2006.

Ueno, O., Kawano, Y., Wakayama, M., Takeda, T.: Leaf vascular system in $\mathrm{C}_{3}$ and $\mathrm{C}_{4}$ grasses: a two-dimensional analysis. Ann. Bot. 97: 611-621, 2006.

Ueno, O., Sentoku, N. Comparison of leaf structure and photosynthetic characteristics of $\mathrm{C}_{3}$ and $\mathrm{C}_{4}$ Alloteropsis semialata subspecies. - Plant Cell Environ. 29: 257-268, 2006.

Uhl, D., Mosbrugger, V.: Leaf venation density as a climate and environmental proxy: a critical review and new data. Palaeogeogr. Palaeoclimatol. Palaeoecol. 149: 15-26, 1999.

Wang, J.Y., Turner, N.C., Liu, Y.X., Kadambot, H., Siddique, M., Xiong, Y.C.: Effects of drought stress on morphological, physiological and biochemical characteristics of wheat species differing in ploidy level. - Funct. Plant Biol. 44: 219234, 2017.

Watanabe, N., Kobayashi, S., Furuta, Y.: Effect of genome and ploidy on photosynthesis of wheat. - Euphytica 94: 303-309, 1997.

Wright, I.J., Reich, P.B., Westoby, M., Ackerly, D.D., Baruch, Z., Bongers, F., Cavender-Bares, J., Chapin, T., Cornellssen, J.H.C., Dlemer, M., Flexas, J., Garnier, E., Groom, P.K., Gullas, J., Hikosaka, K., Lamont, B.B., Lee, T., Lee, W., Lusk, C., Midgley, J.J., Navas, M., Niinemets, U., Poot, P., Prior, L., Pyankov, V.I., Roumet, C., Thomas, S.C., Tjoelker, M.G., Veneklaas, E.J., Villar, R.: The worldwide leaf economics spectrum. - Nature 428: 821-827, 2004.

Xiong, Y.C., Li, F.M., Zhang, T.: Performance of wheat crops with different chromosome ploidy: root-sourced signals, drought tolerance, and yield performance. - Planta 224: 710718, 2006.

Xiong, D.L., Yu, T.T., Zhang, T., Li, Y., Peng, S.B., Huang, J.L.: Leaf hydraulic conductance is coordinated with leaf morphoanatomical traits and nitrogen status in the genus Oryza. - J. exp. Bot. 66: 741-748, 2015.

Zhang, J.L., Zhang, S.B., Chen, Y.J., Zhang, Y.P., Poorter, L.: Nutrient resorption is associated with leaf vein density and growth performance of dipterocarp tree species. - J. Ecol. 103: 541-549, 2015.

Zhang, S.B., Guan, Z.J., Sun, M., Zhang, J.J., Cao, K.F., Hu, H.: Evolutionary association of stomatal traits with leaf vein density in Paphiopedilum, Orchidaceae. - PLoS ONE 7: e40080, 2012

Zhang, S.Q., Shan, L., Deng, X.P. Change of water use efficiency and its relation with root system growth in wheat evolution. Chin. Sci. Bull. 47: 1879-1883, 2002.

Zhang, Y. H., Sun, N.N., Hong, J.P., Zhang, Q., Wang, C., Xue, Q.W., Zhou, S.L., Huang, Q., Wang, Z.M.: Effect of sourcesink manipulation on photosynthetic characteristics of flag leaf and the remobilization of dry mass and nitrogen in vegetative organs of wheat. - J. integr. Agr. 13: 1680-1690, 2014. 